Article

\title{
Selected Properties of Overlaid Magnesium Based Composite Panels for Flooring
}

\author{
Fidan Aslanova ${ }^{1}$, Gozen Elkiran ${ }^{2}$, Salim Hiziroglu ${ }^{3, *}$ and Serkan Ilseven ${ }^{4}$ \\ 1 Department of Environmental Engineering, Near East University, Near East Blvd, Mersin 10, Turkey; \\ fidan.aslanova@neu.edu.tr \\ 2 Department of Civil Engineering, Near East University, Near East Blvd, Mersin 10, Turkey; \\ gozen.elkiran@neu.edu.tr \\ 3 Department of Natural Resource Ecology and Management, Oklahoma State University, \\ Stillwater, OK 74078, USA \\ 4 Faculty of Art and Science, Department of Geography, Near East University, Near East Blvd, Mersin 10, \\ Turkey; serkan.ilseven@neu.edu.tr \\ * Correspondence: salim.hiziroglu@okstate.edu
}

Received: 3 July 2020; Accepted: 17 July 2020; Published: 22 July 2020

\begin{abstract}
The objective of this work was to evaluate some of the mechanical and physical properties of the flooring materials manufactured from panels having magnesia substrate overlaid with oak veneer (Querqus alba) and linoleum sheets. Commercially manufactured panels were used in this work. Bending characteristics, internal bond strength, thickness swelling, and surface quality of the samples were evaluated. The highest modulus of elasticity (MOE) value of $4406 \mathrm{MPa}$ for the sample type-A2 was loaded in the direction of the substrate followed by $3478 \mathrm{MPa}$ for linoleum covered samples which were loaded in the same direction. Internal bond strength values of the panels did not show any significant differences from each other. Dimensional stability of the specimens in the form of thickness swelling for both 2-h and 24-h water soaking tests resulted in values ranging from 0.11 to $0.19 \%$. The surface quality of the samples was not substantially influenced as a function of water exposure. Based on the results in this work magnesium substrate overlaid with oak veneer and linoleum panels could have potential to be used as flooring material with accepted properties.
\end{abstract}

Keywords: composite; oak veneer; linoleum; magnesia; strength properties

\section{Introduction}

Flooring manufactured from solid wood is the most expensive and desired for interior applications among the other materials in residential buildings [1]. Homes with solid wood flooring would be expected to have higher resale value than comparable homes with non-wood floors. The overall value of flooring in construction industry in the USA was about $\$ 2$ billion and $\$ 5.8$ billion in 2009 and 2014, respectively [2]. It is expected that such values will increase over the next two decades with newly developed residential areas due the high rate of the urbanization in the US [2]. Although solid wood is considered as prime product in flooring manufacture, its dimensional stability and high cost are some of the major disadvantages. Therefore there has been great trend over the last several decades shifting from solid wood to engineered composite flooring in the industry not only from the point of cost but also being environmentally friendly.

Typical engineered flooring panels consist of several thin layers of wood veneers of various species constructed similar to plywood being more functional and less expensive than solid wood flooring [1-4]. Dimensional movement of such flooring due to moisture content fluctuation in surrounding environment is very minimal having cross grain orientation of each ply in the member. 
Consequently they are more stable than solid wood flooring with minimum changes in their dimensions as their moisture content values change. Oak, maple, ash, birch, cherry, and beech are the most commonly used species to manufacture solid wood and engineered wood floorings [1,5].

Overall solid wood flooring market has been changing due to its cost in the form of development of laminated flooring which has been widely used in many countries in the last 30 years. [1,2]. Generally laminated flooring is constructed from various layers of elements which are bonded together in the form of a sandwich configuration. High density fiberboard is a composite panel produced from mostly wood waste within the scope of sustainable approach to save overall forest resources. Laminated flooring manufactured from high density fiberboard (HDF) is definitely less expensive than other types of engineered wood flooring [2,6]. Direct pressure lamination is produced by having melamine wear resistance protective finish as the top layer, high decorative print paper with different color and patterns, HDF panel as the core layer and balancing melamine as the backing layer. The main purpose of such construction is to provide dimensional stability to the units [5]. High pressure laminate (HPL) which is also used for flooring has one or two more layers than that of direct pressure lamination (DPL). Assembled panels are compressed using a pressure of 8.5 MPa at an approximate temperature of $160{ }^{\circ} \mathrm{C}$ for $30-40 \mathrm{~s}$. Following the conditioning of the panels they are cut into planks for further processes [1]. Aluminum oxide particles in combination with melamine resin resulting in scratch resistance of the finished product are used as a top wear layer which makes it harder than many solid wood species. Such flooring can be installed in kitchens, bathrooms and other places with high relative humidity but being a hygroscopic material they do not tolerate direct contact of water for long periods of time similar to other wood based floorings. Solid wood flooring has natural irregular grain orientation unlike to engineered floorings or laminate flooring with uniform and homogeneous grain pattern. High pressure laminate flooring is manufactured tongue and groove so that adjacent pieces are interlocked with each other resulting in a solid paneling effect on the floor. Laminated flooring units manufactured from composite panels still have their limitations of high production cost therefore new raw materials are constantly being developed by the producers.

Linoleum and magnesium oxide known as magnesia are two raw materials used as a constructional products including drywall. Linoleum is generally manufactured from the renewable raw material which is linseed oil with addition of calcium carbonate and pigments resulting in flexible sheets [7-10].

Magnesia based products have an excellent resistance against moisture fluctuation in surrounding environment therefore they are widely used in manufacture of as drywall panels. Underlayment is another common use of magnesia based panels in different type of constructions. There are limited commercial production lines in Europe manufacturing magnesia bonded particleboard. In general magnesia oxide is applied to the lignocellulosic materials in a batch blender along with other chemicals and water before it is molded in desired panel size. Another major advantage of magnesia is its low cost which makes it more desirable than wood based underlayment composite panels such as particleboard [2]. However strength properties of magnesia based panels are very poor and unless they are enforced using various types of thick overlays they can easily be broken or split into pieces. In this work commercially manufactured magnesia based panels overlaid with solid oak veneer and thin layer of linoleum were used for the experiments. There are studies carried out related to physical, mechanical and chemical properties of both magnesia and linoleum but there is very limited information on characteristics of panels manufactured from such raw materials as flooring units [2]. Therefore the objective of this work was to determine mechanical as well as physical properties of oak veneer and linoleum overlaid magnesium panels to be used as flooring members. It is expected that data determined in this work would be useful to understand behavior of such panels consequently they can be used more effectively and efficiently during their service life.

\section{Materials and Methods}

Commercially produced two different types of samples having magnesium substrate with a total thickness of $12.00 \mathrm{~mm}$ having linoleum and oak wood veneer overlays were used for the tests as 
illustrated in Figure 1. Both linoleum and oak veneer had $2.00 \mathrm{~mm}$ thickness. A total of 60 samples, 30 for each type were tested employing a Comten Universal Testing Unit Model DMC-026S equipped with $1000 \mathrm{~kg}$ load cell based on ASTM standards to determine their modulus of elasticity (MOE), modulus of rupture (MOR) as well as internal bond strength (IB) (Figure 1) [11] Samples were centrally loaded on laminated and non-laminated sides of each sample to determine if there was any influence of loading direction on structural characteristics of the members. Figure 2 shows schematics of sample type in regard to their loading directions.

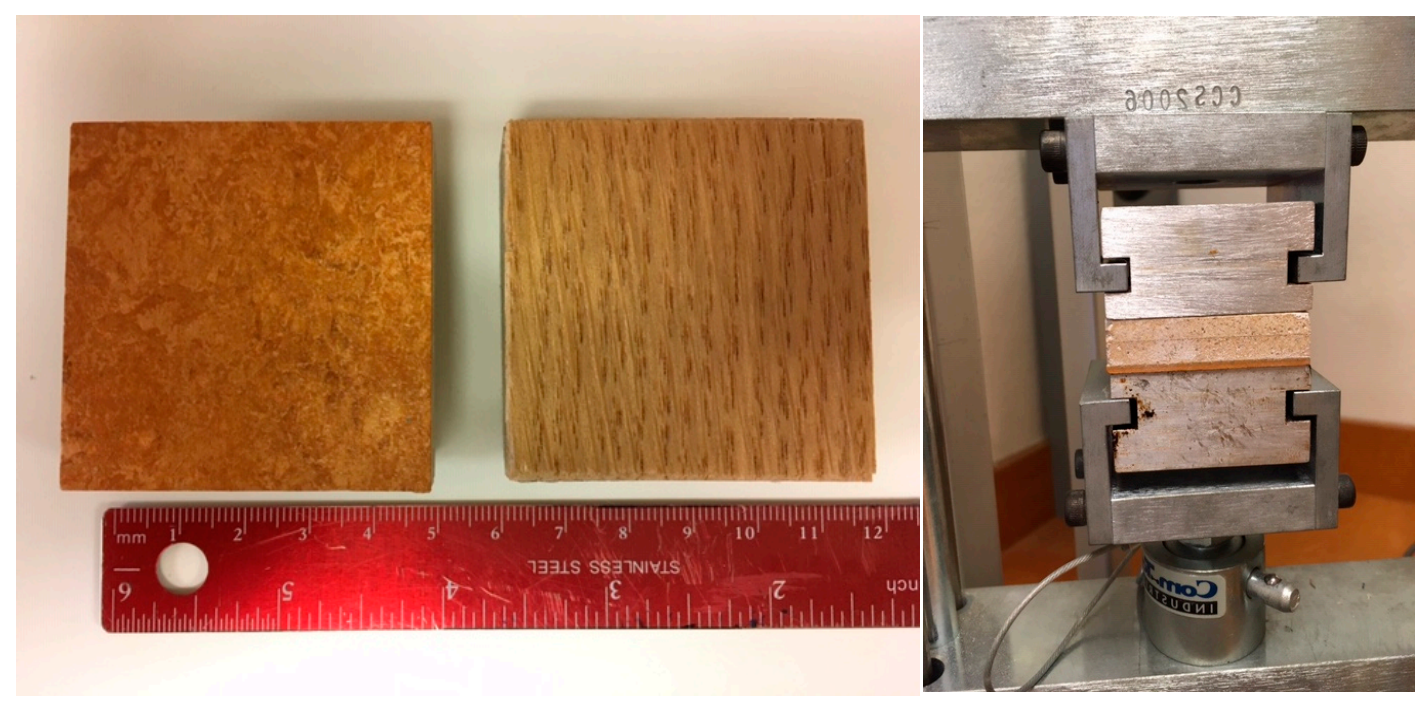

Figure 1. Internal bond strength (IB) samples and IB test set-up showing the cross section of the sample. (Left is linoleum overlaid and the right one is oak veneered sample).

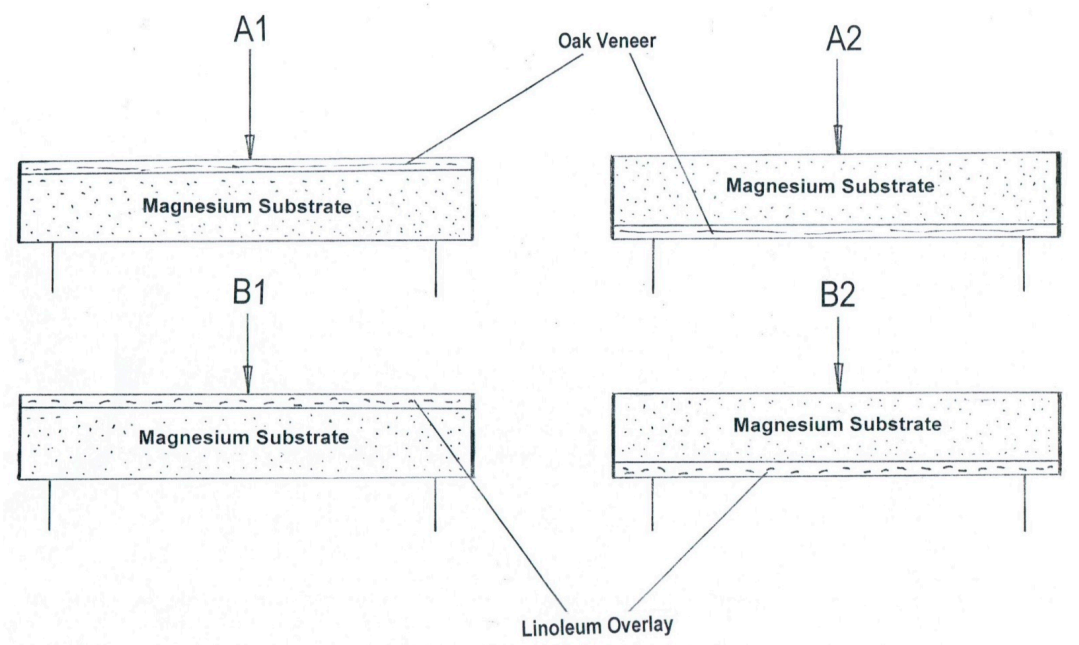

Figure 2. Schematics of the samples based on loading direction.

A total of forty samples with dimension of $50 \mathrm{~mm}$ by $50 \mathrm{~mm}$ in panel thickness were used for internal bond (IB) strength test on Comten Testing Unit described above. Samples were glued to aluminum block using a hot-melt adhesive in the form of sandwich configuration and they were kept in climate room having a temperature of $20^{\circ} \mathrm{C}$ and relative humidity of $65 \%$ for several days before tests were carried out [11]. Crosshead speed of $3 \mathrm{~mm} / \mathrm{min}$ was used for both bending and IB tests on the Comten Unit. For both bending and internal bond tests dimensions and weights of each sample were measured at accuracy levels of $0.1 \mathrm{~mm}$ and $0.01 \mathrm{~g}$, respectively to determine their average density which was found as $1.09 \mathrm{~g} / \mathrm{cm}^{3}$. 
Dimensional stability plays a very important role during the service life of the flooring panels. Therefore 10 samples in $120 \mathrm{~mm}$ by $120 \mathrm{~mm}$ from each type panel were soaked in water to determine their thickness swelling as a result of 2-h and 24-h water exposure. The thickness of each sample was also measured at four corners after 2-h and 24-h soaking time at accuracy level of $0.1 \mathrm{~mm}$ to determine their thickness swelling values.

Roughness of the flooring panels is important for application of varnish or any kinds of maintenance coatings. It is a fact that any rough surface would require higher amount of varnish increasing overall production cost. Roughness can be defined as measure of fine irregularities on a surface $[4,12]$. Surface instability is somehow a latent condition and may never happen unless favorable environmental conditions exist. A total of $40,50 \mathrm{~mm}$ by $50 \mathrm{~mm}$ samples were used for roughness measurements. After taking initial measurements at dry condition the samples were soaked in water for 24-h and their roughness measurements were retaken from the surface of each sample. A stylus type equipment SRT-6200 unit was employed for the measurements. The equipment consists of the main unit and pick-up with a skid type diamond stylus with a $5 \mu \mathrm{m}$ tip radius and $90^{\circ}$ tip angle. Four random measurements were taken over $15 \mathrm{~mm}$ tracing length from the surface of each sample. Two roughness parameters, namely average roughness $\left(R_{a}\right)$ and mean peak-to-valley height $\left(R_{z}\right)$ were used to quantify the roughness of the specimens. Description and principles of these three roughness parameters are presented in past studies [12-14]. Only oak veneer surfaces were considered for roughness test since linoleum is being non-hygroscopic material and having very rough surface.

Finally vertical density profiles of the samples were also tested using an x-ray type density profilometer to be able to compare densification of the face and core portion of the panels.

\section{Results and Discussion}

Overall properties of the samples are displayed in Table 1. The highest MOE and MOR values of $4406 \mathrm{MPa}$ and $3478 \mathrm{MPa}$ were found the oak and linoleum overlaid samples loaded on the side of magnesia substrate. Oak overlaid samples had significantly higher bending characteristics as compared to those of linoleum samples due to nature of solid oak veneer. As it is a well-known fact that wood is a natural composite having much higher strength properties as compared to any kind of wood based composites such as particleboard or fiberboard. When strength properties of oak veneer are compared to that of linoleum, soft and pliable properties of linoleum would be responsible for such finding. Similar results were also observed in a preview study carried out panels made using walnut wood veneer as overlay [2,15]. MOE and MOR values of the samples are also illustrated in Figure 3.

Table 1. Test results of the samples. (Numbers in parenthesis are standard deviation values).

\begin{tabular}{|c|c|c|c|c|c|c|c|c|c|}
\hline \multirow{3}{*}{$\begin{array}{l}\text { PANEL } \\
\text { TYPE }\end{array}$} & \multirow{3}{*}{$\begin{array}{l}\text { MOE } \\
\text { (MPa) }\end{array}$} & \multirow{3}{*}{$\begin{array}{l}\text { MOR } \\
(\mathrm{MPa})\end{array}$} & \multirow{3}{*}{$\begin{array}{c}\text { IB } \\
(\mathrm{MPa})\end{array}$} & \multirow{2}{*}{\multicolumn{2}{|c|}{ TS (\%) }} & \multicolumn{4}{|c|}{$\begin{array}{c}\text { ROUGHNNESS } \\
\text { PARAMETERS }(\mu \mathrm{m})\end{array}$} \\
\hline & & & & & & \multicolumn{2}{|c|}{ DRY } & \multicolumn{2}{|c|}{24 h SOAKED } \\
\hline & & & & $2 \mathrm{~h}$ & $24 \mathrm{~h}$ & $\mathbf{R}_{\mathbf{a}}$ & $\mathbf{R}_{\mathbf{Z}}$ & $\mathbf{R}_{\mathrm{a}}$ & $\mathbf{R}_{\mathbf{Z}}$ \\
\hline A1 & $\begin{array}{c}2822 \\
(190.18)\end{array}$ & $\begin{array}{l}21.16 \\
(1.82)\end{array}$ & $\begin{array}{c}1.10 \\
(0.10)\end{array}$ & $\begin{array}{c}0.13 \\
(0.01)\end{array}$ & $\begin{array}{c}0.18 \\
(0.09)\end{array}$ & $\begin{array}{c}8.30 \\
(0.61)\end{array}$ & $\begin{array}{c}56.20 \\
(2.2)\end{array}$ & $\begin{array}{l}9.30 \\
(1.5)\end{array}$ & $\begin{array}{l}70.5 \\
(3.4)\end{array}$ \\
\hline $\mathrm{A} 2$ & $\begin{array}{c}4406 \\
(410.20)\end{array}$ & $\begin{array}{l}38.15 \\
(3.71)\end{array}$ & $\begin{array}{c}1.13 \\
(0.12)\end{array}$ & $\begin{array}{c}0.14 \\
(0.09)\end{array}$ & $\begin{array}{c}0.19 \\
(0.08)\end{array}$ & $\begin{array}{c}7.90 \\
(0.45)\end{array}$ & $\begin{array}{l}54.39 \\
(2.9)\end{array}$ & $\begin{array}{l}8.88 \\
(2.1)\end{array}$ & $\begin{array}{l}74.9 \\
(4.3)\end{array}$ \\
\hline B1 & $\begin{array}{c}2716 \\
(230.40)\end{array}$ & $\begin{array}{l}10.54 \\
(1.32)\end{array}$ & $\begin{array}{c}1.06 \\
(0.08)\end{array}$ & $\begin{array}{c}0.11 \\
(0.08)\end{array}$ & $\begin{array}{c}0.12 \\
(0.01)\end{array}$ & - & - & - & - \\
\hline B2 & $\begin{array}{c}3478 \\
(310.22)\end{array}$ & $\begin{array}{l}22.29 \\
(2.14)\end{array}$ & $\begin{array}{l}1.08 \\
(0.09)\end{array}$ & $\begin{array}{c}0.10 \\
(0.09)\end{array}$ & $\begin{array}{c}0.13 \\
(0.12)\end{array}$ & - & - & - & - \\
\hline
\end{tabular}




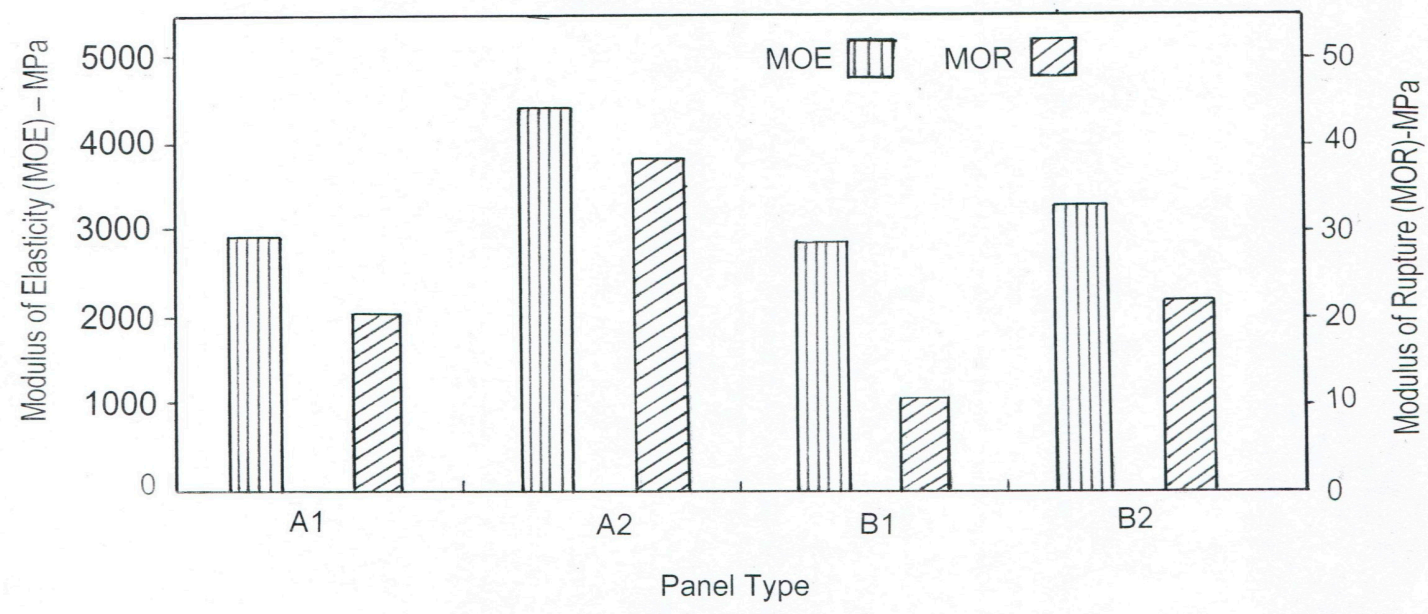

Figure 3. Bending characteristics of the samples.

Application of load during the service life of the flooring panels is not that critical however it was the objective to determine magnitude of brittleness of magnesium substrate within the scope of this work [15-17]. It appears that both oak veneer and linoleum overlaid samples developed higher resistance resulting in enhanced bending properties of the panels in the case of application of load on substrate direction. When load was applied on overlaid direction, both types of overlays had lower stiffness resulting in lower MOE values consequently also lower bending strength values.

Internal bond strength values of the samples ranged from 1.06 MPa to $1.13 \mathrm{MPa}$ revealing no noticeable difference between two types of specimens as can be seen in Figure 4. All samples had failure between magnesium substrate and overlays with exception of several glue failures. Overall findings of IB strength values suggest that the glueline between magnesium substrate and overlays were quite strong and no peeling or separation would be expected during service life of these flooring panels [18].

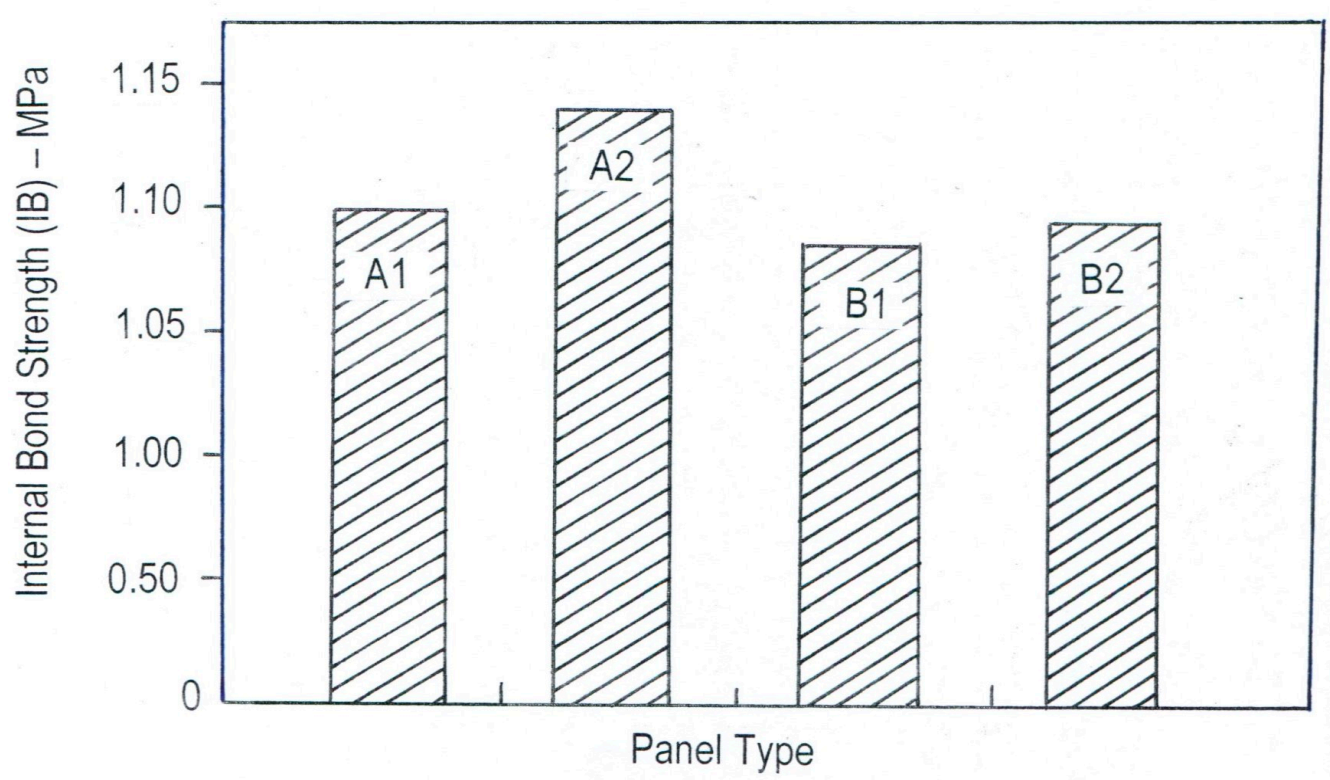

Figure 4. Internal bond strength values of the samples. 
Linoleum overlaid samples had very insignificant thickness swelling ranging from $0.10 \%$ to $0.13 \%$ for $2 \mathrm{~h}$ and $24 \mathrm{~h}$ water soaking, respectively, as shown in Figure 5 Being hygroscopic material solid wood veneer overlaid samples had higher thickness swelling values of up to $0.19 \%$ which is still considered very low. As a result of water soaking test none of the samples showed any deterioration with exception of oak veneered samples had some roughness due to their hygroscopic nature. It appears that such products can be used where there is high humidity fluctuation without having any problems $[19,20]$. It can be stated that dimensional stability of the samples is satisfactory. A past study investigated walnut overlaid magnesium substrate flooring panel also determined comparable thickness swelling values of the samples [2].

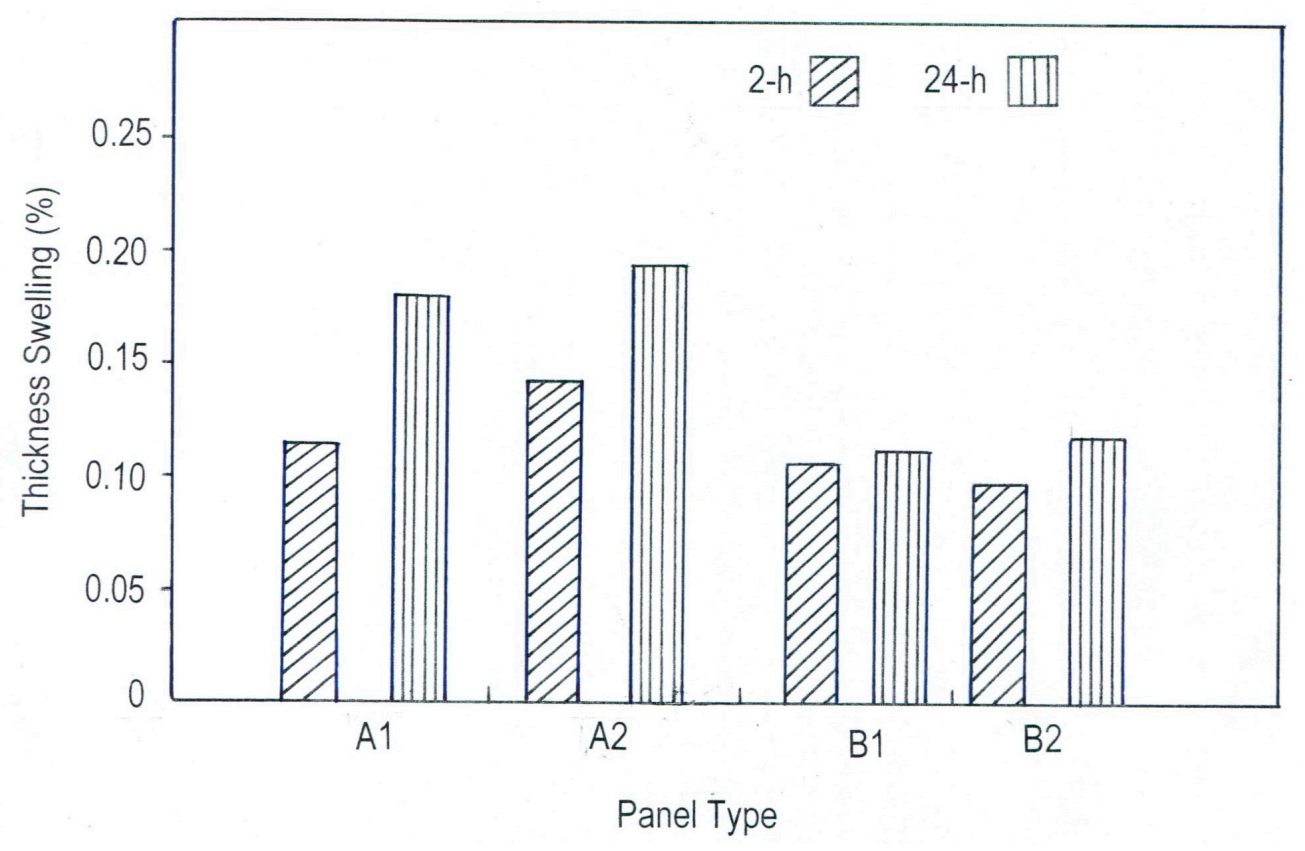

Figure 5. Thickness swelling of the samples.

As can be seen Table 1 surface roughness values of the samples in the form of $R_{a}$, and $R_{z}$, did not show any significant difference as a result of exposure them to $24 \mathrm{~h}$ water exposure. Initial $\mathrm{R}_{\mathrm{a}}$ and $R_{z}$ values of oak overlaid type A1 sample were $8.30 \mu \mathrm{m}$ and $56.20 \mu \mathrm{m}$, respectively. Corresponding values of $9.30 \mu \mathrm{m}$ and $70.15 \mu \mathrm{m}$ and were found after they were soaked in water. A study carried out to determine walnut overlaid of similar product found lower roughness values [2,4]. It is known that oak is a porous species having large ray cells creating relatively rough surface. Higher surface roughness values of oak veneer found in this work could be related anatomical structure of this species.

Density profile is an important data to evaluate overall cross section densification of the panels. Both types of samples had similar density profiles to each other. Magnesium panels were constructed combining two plates together during manufacturing this can dearly be observed in a typical density profile depicted in Figure 6. 


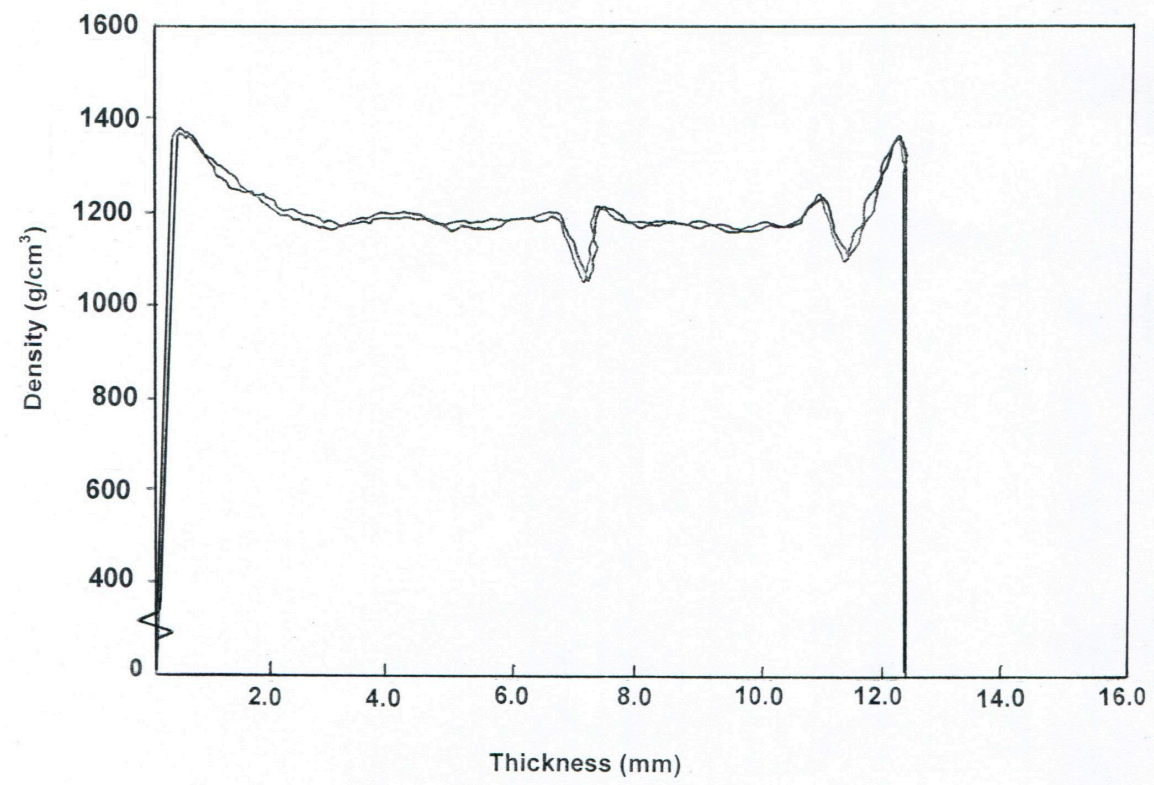

Figure 6. Density profile of oak veneered sample.

\section{Conclusions}

Based on findings in this work bending properties in the form of MOE and MOR of the samples were determined to be higher than typical particleboard and fiberboard and could be used as underlayment for flooring purpose based as American National Standard Institute A-208.2 [21]. Specimens also had satisfactory IB strength values considering the peeling of the overlays from the substrate. Linoleum overlays samples had better dimensional stability and resistance against water exposure than that of veneered samples. It appears that both types of panels have great potential to be used as a flooring material when there is high level of relative humidity due to their very low thickness swelling values. Exposure of the samples to high humidity did not create a significant deterioration in the form of surface roughness. Such overlaid types of panels, having magnesium substrate could be considered as an excellent flooring material. One disadvantage would be their high density resulting in expensive transportation cost.

Author Contributions: Conceptualization, S.H. and F.A., S.I.; Data Curation, G.E., F.A., S.I., and S.H.; Investigation Resources, S.H. and F.A.; Writing-review and editing, S.H. All authors have read and agreed to the published version of the manuscript.

Funding: This research received no external funding.

Acknowledgments: The authors extend their appreciation to the Department of Civil Engineering and Environmental Science for their in kind support.

Conflicts of Interest: The authors declare no conflict of interest

\section{References}

1. Kalaycioglu, H.; Hiziroglu, S. Évaluation of surface characteristics of laminated flooring. J. Build. Environ. 2004, 1, 456-762. [CrossRef]

2. Dilik, T.; Hiziroglu, S. Some properties of linoleum and wood laminated flooring Panels with magnesium substrate. Bioresources 2015, 10, 1667-1674. [CrossRef]

3. Hiziroglu, S. Laminated veneer lumber (LVL) as a construction material. In Food and Agricultural Products Center (FAPC) Fact Sheet-163; 2008; p. 3. Available online: https://extension.okstate.edu/fact-sheets/laminatedveneer-lumber-lvl-as-a-construction-material.html (accessed on 3 July 2020).

4. Hiziroglu, S.; Graham, M. Effect of press closing time and target thickness on surface roughness of particleboard. For. Prod. J. 1998, 48, 50-54. 
5. Landry, V.; Blanchet, P.; Eiedl, B. Mechanical and optical properties of clay-based nanocomposites coating for flooring. Prog. Org. Coat. 2010, 67, 381-388. [CrossRef]

6. Hiziroglu, S. Surface roughness analysis of wood composites: A stylus method. For. Prod. J. 1996, 46, 67-72.

7. Amiandamhen, S.O.; Meincken, M.; Tyhoda, L. Magnesium based phosphate cement binder for composite panels: A response surface methodology for optimization of processing variables in boards produced from agricultural and wood processing industrial residual. Ind. Crops Prod. 2016, 94, 746-754. [CrossRef]

8. Lojka, M.; Jankosky, O.; Jihckova, A.; Lauermannova, A.; Antoncik, F.; Sedmidubsky, D.; Pavlik, Z.; Pavlikova, M. Thermal stability and kinetics of formulation of magnesium oxychloride phase $3 \mathrm{Mg}(\mathrm{OH})_{2} \mathrm{MgCl}_{2} 8 \mathrm{H}_{2} \mathrm{O}$. Materials 2020, 13, 767. [CrossRef] [PubMed]

9. Abdel-Gawwad,H.A.; Abo-El-Enein, S.A.; Heikeal, M.; Abd El-Aleem, S.; Amer, A.; El-Kattan, I.M. Synergistic effect of curing conditions and magnesium oxide addition on the physico-mechanical properties and firing resistivity of Portland cement mortar. Constr. Build. Mater. 2018, 176, 676-689. [CrossRef]

10. Liu, Z.; Wang Huang, J. Experimental investigation on properties and microstructure of magnesium oxychoride cement prepared with caustic magnesite and dolomite. Constr. Build. Mater. 2015, 85, 247-255. [CrossRef]

11. ASTM-D-1037. Method D.1037. Evaluating the Properties of Wood Based Fiber and Particle Panel Material; American Society for Testing and Materials (ASTM): West Conshohocken, PA, USA, 1999.

12. Mummery, L. Surface Texture Analysis. The Handbook; Hommelwerke: Muhlhausen, Germany, 1993; 106p.

13. Merola, M.; Ruggiero, A.; De Mattia, J.S.; Affatato, S. On the tribological behavior of retrieved hip femoral heads affected by metallic debris. A comparative investigation by stylus and optical profilometer for a new roughness measurement protocol. Measurement 2016, 90, 365-371. [CrossRef]

14. Hiziroglu, S.; Holcomb, R.; Wu, Q. Particleboard manufacture from Eastern Redcedar. For. Prod. J. 2002, 52, $72-76$.

15. Gao, Z.; Zhang, A.; Li, S. The resistance to high temperature of magnesia phosphate cement paste containing wallastonite. Mater. Struct. 2015, 49, 1-12.

16. Manalo, A.C.; Aravinthan, T. Behavior of glued fiber composite sandwich structure in flexure: Experiment and fiber model analysis. Mater. Des. 2012, 39, 458-468. [CrossRef]

17. Rio Moenini, M.; Santa Cruz Astorqui, J.; Hernandez Oliveres, F. New fabricated elements of lightened plaster used for partitions. Constr. Build. Mater. 2005, 19, 487-492.

18. Hossain, K.M.A. Axial load behavior of profiled composite walls. Ipenz Trans. 2000, 27, 1-7. [CrossRef]

19. Xu, B.; Ma, H.; Hu, C. Influence of curing regimes on mechanical properties of magnesium oxychloride cement based composites. Constr. Build. Mater. 2016, 102, 613-618. [CrossRef]

20. Nazerian, M.; Sadeghiipanah, V. Cement-bonded particleboard with a mixture of wheat straw and poplar wood. J. For. Res. Jpn. 2013, 24, 381-390. [CrossRef]

21. ANSI. Surface Texture Surface Roughness, Waviness and Lay. B46.1; The American society of Mechanical Engineers: New York, NY, USA, 1985; p. 43.

(C) 2020 by the authors. Licensee MDPI, Basel, Switzerland. This article is an open access article distributed under the terms and conditions of the Creative Commons Attribution (CC BY) license (http://creativecommons.org/licenses/by/4.0/). 